
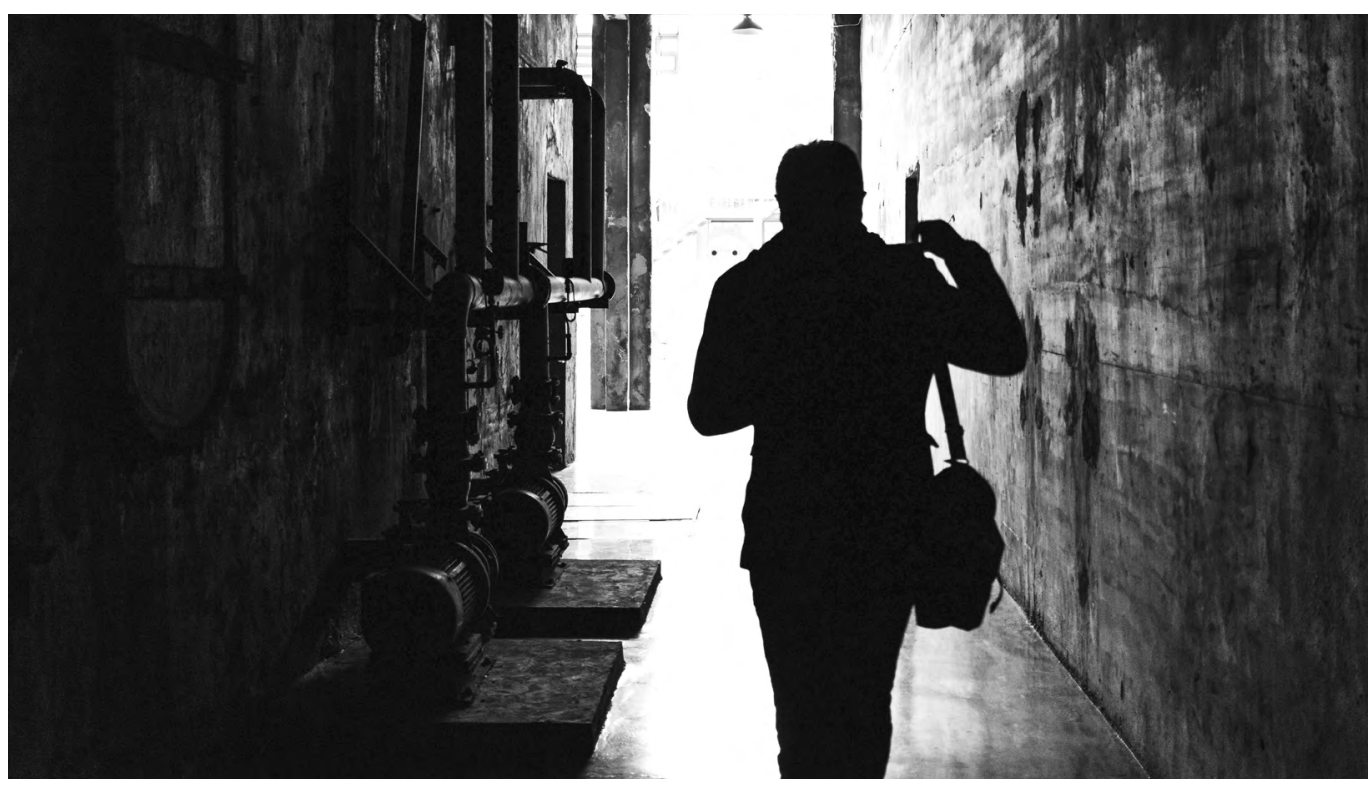

From the Dark to Light. PC: (CC) Gauthier Delecroix.

\section{The Work of Culture \\ Of Barons, Dark Academia, and the Corruption of Language in the Neoliberal University}

Two recent books shed light on the functioning of different types of university. In his novel Italian Life (2020), Tim Parks describes the baronial university of yore, while the now predominant neoliberal university is at the centre of Peter Fleming's Dark Academia (2021). This essay argues that the two models of academia are actually far more similar than we generally think.
There was a time when academia was society's refuge for the eccentric, brilliant, and impractical. No longer. It is now the domain of professional self-marketers. As for the eccentric, brilliant, and impractical: it would seem society now has no place for

them at all. - David Graeber (2015: 134-35)

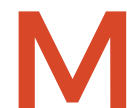

uch has been written in recent years about the degeneration of neoliberal academia, which makes for odd and discomforting reading when you are part-as both victim and accomplice-of that system, but few writers have been able to describe the perversion of the system in terms as vivid and inventive as the late anthropologist David Graeber. According to Graeber (2015: 141), the commercialisation and bureaucratisation of academia have led to a shift from 'poetic technologies' to 'bureaucratic technologies', which is one of the reasons why today we do not go around on those flying cars promised in 
the science fiction of the past century. As universities are bloated with 'bullshit jobs' and run by a managerial class that pits researchers against each other through countless rankings and evaluations, the very idea of academia as a place for pursuing groundbreaking ideas dies (Graeber 2015: 135; 2018). As conformity and predictability come to be extolled as cardinal virtues, the purpose of the university increasingly becomes simply to confirm the obvious, develop technologies and knowledge of immediate relevance for the market, and exact astronomically high fees from students under the pretence of providing them with vocational training (hence the general attack on the humanities). But is that all there is to it?

In this essay, I will look at two recent books that shed light on two ideal types of university: the baronial university of yore, described by Tim Parks in his novel Italian Life: A Modern Fable of Loyalty and Betrayal (2020); and the now predominant neoliberal university, which, in theory, should have signalled the demise of this old model, as discussed by Peter Fleming in Dark Academia: How Universities Die (2021). Based on my reading of these two books and my personal experiences in various universities over the past decade or so, I will argue that the two models of academia are far more similar than we generally think.

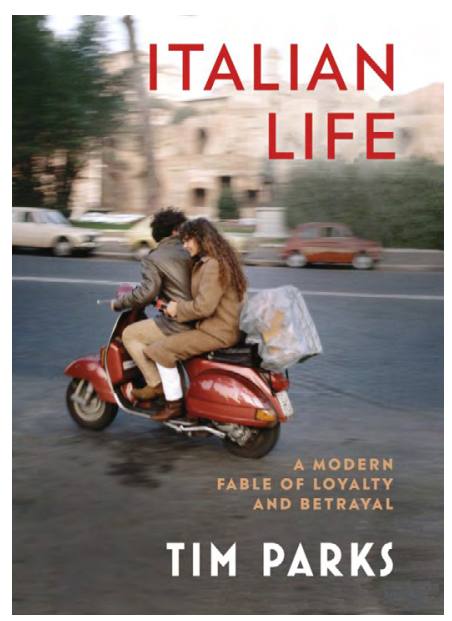

Cover of Tim Parks' Italian Life, published by Harvill Secker in 2020.

\section{Italian Life}

Drawing from his four decades of experience in Italy, Tim Parks in Italian Life takes readers into the labyrinth of Italian academic life. Read from the standpoint of the neoliberal model of academia that has taken root today, the novel is like a trip back in time-a feeling of temporal dislocation that is reinforced by the geographical displacement experienced by the two protagonists of the story: the mature James, who comes from England, marries an Italian woman, and enters Italian academia as an English-language and literature teacher; and Valeria, a young woman from a small town in Italy's far south who moves to Milan for her studies. Their paths do not intersect until late in the novel, but their converging life trajectories offer a perfect opportunity for the author to explore the oddities of Italian academic life from the perspective of two insiders/outsiders.

For this essay, I will focus on James's experience. He has studied literature at Oxford and Yale, so he feels more than qualified to become a professor at some point. Still, after a few years spent teaching English to university students in a provincial university in northern Italy, the intricacies of Italian academia still elude him. He talks to the powers that be about his chances of landing a proper professorial job, but they are sceptical. It has nothing to do with his skills, they say. It is just that, even if Italy has a system of obligatory and open public concorsi for research grants and academic positions, "the candidates who come out on top are almost always those who have worked closely with the local professor who sits on the interviewing board' (p. 10). They tell him that in 99 out of 100 cases, it will be the internal candidate who will win the concorso, regardless of their competence. As a puzzled James wonders why external candidates would ever bother applying for a job they know they have no chance of getting, his colleagues explain that it is a way for them to 'indicate their submission to the system': 'They play the game, as if it was fair. They show themselves around. Perhaps they will impress someone on the commission who might then, in the future, invent a concorso for them without an internal 
candidate' (p. 11). To 'show himself around', James sends his CV to 30 universities, but only one institution, in Milan, replies, offering to let him teach a literature course on a contract basis, paid by the hour. This gig lasts seven years, until the institution opens a researcher position-the first step for James to become a tenured professor. After he overcomes formidable bureaucratic hurdles, he eventually manages to get the job. From that moment on, he basically does the same things as before, but with better pay.

The very procedures of Italian academia are confusing to James. Having been educated in British and American universities, he feels Italian students have a rather easy life. The oral exam is the norm, and it is administered by a student's own teacher, so Italian students 'study [their own] teacher as much as [their subject], the way a public speaker studies his audience as much as his brief' (p. 36). He notices that some students even go as far as to dress the way they expect their teacher would like them to dress. There are seven appelli every year-that is, seven chances to take one exam before having to take a class all over again, which is a nightmare for the professors who find the same students taking their chances over and over without ever bothering to properly prepare. Even the marking system looks weird to James's eyes: exams are evaluated in thirtieths, with 18 being the lowest mark to pass, while the final grade for an Italian degree is expressed in one hundred and tenths. The language is also odd, childish almost. For instance, students are never said to fail:

Bocciare is the word most commonly used for fail, in the context of exams. Oddly, the idea seems to have come from the game of bowls, bocce, where bocciare means to use your ball to push an opponent's ball away from the objective. It's a sneaky, aggressive move that prevents another person from winning. Sono stato bocciato. I've been pushed away. I've been, if not actually excluded, then distanced. Mandato via, sent away, is another expression for failing an exam. Or respinto, rejected. I've been rejected. In all these expressions there is the suggestion of an agent-a professor, a teacher, a commission- who has done this unkind thing to you. One never says, as in English, the simple, intransitive, I failed. (p. 39)

Idiosyncrasies like this seem to suggest that the Italian former minister who called Italian youths bamboccioni ('big babies') back in 2009 may have had a point. But Parks takes care to also show us the other side of Italian academic life through the eyes of Valeria, who finds herself having to navigate the intrusiveness of her family, the inappropriate behaviour of some of her professors, and the incompetence of others. Reading Valeria's side of the story, we cannot but realise that life is not all roses for these students, especially those who, like Valeria, want to pursue an academic career after graduation.

The big beast of Italian academic life, though, is the figure of the baroni-powerful senior academics who manage to carve out their own fiefdoms within the university. Baroni always demand loyalty and perceive any minor slight as a betrayal to be met with retaliation (hence the subtitle of Park's novel, 'A Modern Fable of Loyalty and Betrayal'). One day, 18 months after winning his concorso, James receives a phone call from the secretary of the university's rector, who asks him to meet the big man in his home. Full of expectations, James goes to the meeting only to discover that the rector wants him to translate into English his 437-page book-a pointless treatise on popular philosophy. He naively refuses and, for the next three years, the barone completely ignores him, until he is ousted in an academic coup d'état. Still, despite all this, Parks has some kind words for the Italian universities of those years:

The university back then, in the nineties, the early noughties, was certainly a quarrelsome place, sometimes a childish place and always a frustrating place, but, in the end, functional, in the end, benign. If learning did not flourish quite as one might have hoped, still it wasn't altogether blighted or systematically sabotaged. The limitations were those of ordinary people jockeying for position within the framework of a national system apparently designed to make everything as difficult as 
possible for everyone and in every regard. Rectors and Heads of Department were regularly elected or not elected and generally accepted the verdicts of their peers. Hiring was never strictly meritocratic, but nor did it entirely ignore merit. Gripe as you might, you could think of this place as your home. your family, albeit a slightly dysfunctional one. (pp. 168-69)

As Italian universities discover the Anglo-American model of 'fundraising', they also realise that for cultural reasons it is very unlikely that former students, however successful, would ever donate to the university, so they resort to the only alternative: recruiting people with powerful contacts who will be able to attract funds from outside. This shift opens the door for the arrival of Professor Beppe Ottone, a Freemason who sat on the board of several banks and insurance companies, a former senator with powerful political connections. He arrives with his right-hand woman, Professor Bettina Modesto, an inept academic who throughout the book is as much feared as laughed at (always behind her back, of course). The following passage about a keynote speech she gives at the inauguration of the new academic year builds Professor Modesto up into the perfect stereotype of the vacuous academic who will soon fill the managerial ranks of the bureaucratic, neoliberal university:

Modesto sipped some more water, shifted her weight from one high heel to the other. announced, 'and hence in conclusion' for the third time, then launched into another sentence as long as it was formless and meaningless. The words 'Lacanian miseen-scène' ... flashed by. James was lost, but also awed ... Had the audience been made up of independent agents they would have been laughing their collective head off. As it was, quite a number of students were now slipping away. The heavy black curtain over the rear exit twitched every few seconds as eager hands pushed it aside. But the professors were obliged to sit in solemn silence, as
Modesto now announced her conclusion for the fourth time. (p. 205)

The arrival of Ottone and Modesto is a landmark event that signals the passage from the old baronial university, which still had some semblance of collegiality, to a more openly authoritarian model. As the two new arrivals take over the university, James and his colleagues begin to feel 'how unwise it would be, in department meetings and $\mathrm{PhD}$ commissions, to contest the opinions of Ottone and Modesto' (p. 179). A new culture of unanimity quickly takes root, taking most academics unaware, including James: ‘[O] nly much later, far too late, did James understand that an organisation in which all decisions are unanimous is an organisation whose members live in fear' (p. 172). Should you displease them, the new baroni not only ignore you-as had the philosopher rector after James refused to translate his oeuvre-they do their utmost to destroy you, as both James and Valeria will soon discover (as this is a novel, I will not spoil the story by providing more details here).

\section{Dark Academia}

While Tim Parks' Italian Life gives us some insight into the baronial model of university, in Dark Academia, Peter Fleming takes us on a tour of the neoliberal university with which it is being replaced. What is 'dark academia' according to Peter Fleming? On one side, the term reflects the mood of resignation that dominates among academics today, at least those who still believe the main purpose of universities should be the pursuit and dissemination of knowledge. Fleming tells us that we are now at a stage when corporatisation 'has been so exhaustive (on a financial, organisational, individual and subjective level) that reversing it in the current context feels nearly impossible. Rather than fighting back, most academics have merely found ways to dwell in the ruins' (p. 5). This purely capitalist realism-the Jamesonian idea that it is easier to imagine the end 
of the world than the end of capitalism-is what characterises academic life today, leading to widespread dark feelings of powerlessness and resignation. On the other side, 'dark academia' reflects the fact that over the past couple of decades, not only has the neoliberal university seen an increase in the number of bureaucrats in positions of power, to a point where they now most often outnumber academic staff, but also this regular bureaucracy is shadowed by a 'troubling twin' in the form of this 'darkocracy' that has 'converted universities into factories of sadness'. According to Fleming, these are

power networks controlled by functionaries in these institutions. Although some in their ranks may look like academics, many have been trained elsewhere or are career administrators. And those who were once scholars are now better labelled as para-academics, since they've acquired the 'boss syndrome' and find themselves looking down on their erstwhile colleagues with mild disdain. (p. 53)

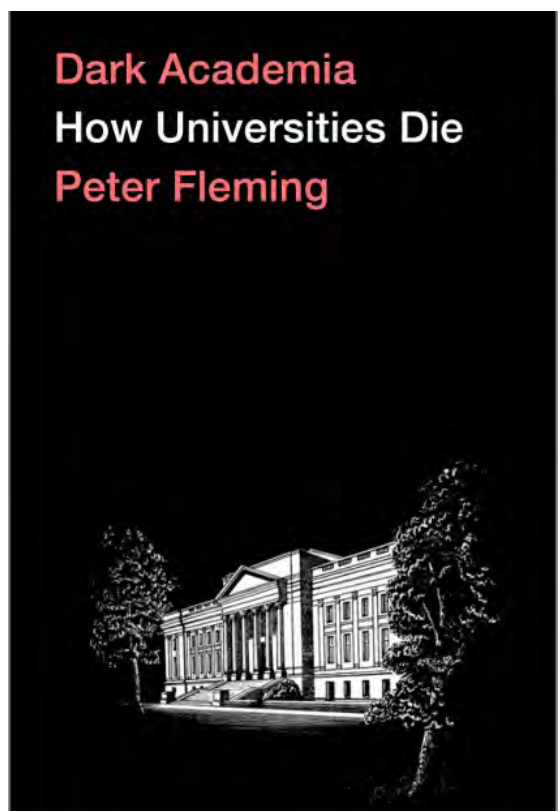

Cover of Peter Fleming's Dark Academia, published by Pluto Books in 2021.
Instead of discussing in detail the political, economic, and philosophical sides of the transition to this darker mode of academia, Fleming chooses to focus on the subjective dimension of how neoliberal academia affects the mental health of those who take part in it. Drawing from Oliver James's work positing a correlation between rising rates of mental distress and the neoliberal mode of capitalism, Mark Fisher (2009: 19) once argued that it is necessary to reframe the growing problem of stress and distress in capitalist societies not as a private issue but as a structural one. Mirroring this analysis in the context of academia, throughout the book, Fleming repeatedly delves into how academic life impacts the mental health of university staff and students, leading to suicide, self-harm, depression, chronic stress, and anxiety. Lecturers, we are told,

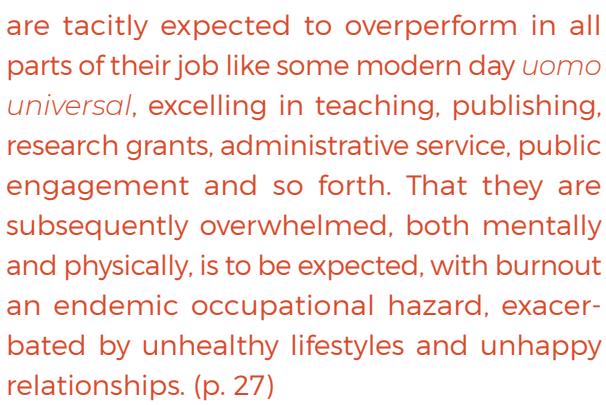

Students do not fare any better: far from being treated with kid gloves and pampered, they are drowning in debt, under immense pressure to complete their degrees, and often holding down part-time jobs.

Atomisation and isolation are the inevitable consequences. Fleming points out that while some have compared the obsession with target performance outputs of contemporary university administration to the Stakhanovite movement in Joseph Stalin's Soviet Union, the parallel is somehow misleading because at least the Soviets ranked teams rather than individuals, unlike the neoliberal university. According to Fleming, it is this individualising tendency blended with the blind abstractions of quantifications that allows the Edu-Factory to hone its own unique brand of "terror"' (p. 71). This extreme atomisation emerges clearly from tragic stories like that of Thea Hunter, 
an adjunct professor in the United States whose health deteriorated due to her stressful and peripatetic life, constantly driving from one campus to another to deliver lecture after lecture, with no health insurance or other benefit whatsoever. When her health failed, she was unable to afford medical care and, when she died, nobody claimed her corpse for three weeks, until the hospital managed to track down a former colleague whom she had befriended years earlier. Or the death of Mason Pendrous, a 19-year-old University of Canterbury (New Zealand) student, who was found dead in his campus dormitory room in 2019. He died of natural causes, but it took one month for other people in the dormitory to notice the smell and realise that something was horribly wrong behind the door that never opened.

And this isolation leads not only to depression, but also to suicide after suicide. Dark Academia cites universities where the suicide rate among students and staff is higher even than those recorded among Foxconn workers in the early 2010s, when the Taiwanese electronics manufacturer made headlines for a series of suicides among its young employees in southern China. And while all suicides are shocking, they do not always make for stories as sensational as the self-immolation of an undergraduate student in France in November 2019 or the suicide in September 2019 of a counsellor at the University of Pennsylvania whose job it was to prevent students from acts of self-harm. It is the silence that surrounds the phenomenon, despite its pervasiveness, that is striking, and which Fleming points out. The reason these situations seldom make headlines is that, adopting a strategy that was also in Foxconn's playbook a decade ago, universities attempt to deflect attention from the root structural causes of these actions towards supposed pre-existing psychological conditions and/or the personal situations of the victims, or by emphasising that modern society as a whole is to blame. Meanwhile, HR departments churn out platitude after platitude about work-life balance, partly in a futile attempt to prevent their staff from suffering from (expensive) burnout, partly so that, when something inevitably happens, the university can be protected from compensation claims.
Along with academic friends, I often tinkered with the idea of writing a 'bestiary' of the contemporary university. In this booklet, we would describe the most common 'types' of academics you are likely to meet in the corridors of the neoliberal university, describing them in the fashion of medieval catalogues of imaginary beasts. Fleming does just that. In discussing the academic star complex in the neoliberal university, he distinguishes between academic superstars, wannabe starlets, and failed starlets, pointing out that all types are part of the same social field. He shows how academic stardom is enabled by the exploitation of the lowest rungs of the academic workforce (in particular, casual workers) and how university managers make active use of starlets to sow division among their workforces. He singles out failed academic starlets for particular scorn:

\section{While most failed academic starlets remain harmless, retreating into the shadows of mass academia, some decide to enter middle-man- agement instead. Given the aforementioned umbrage, this can spell trouble for those under their charge. These failed starlets often seek revenge and can easily become Hitler- like taskmasters in the process. (p. 123)}

Of course, the targets of this revenge are always those below and never those above. It is telling that Fleming's categorisation does not include academics who reject the mechanisms of the academic star complex and 'embrace failure'-to quote from Halberstam (2011)-that is, scholars who actively refuse to participate in the rat race of contemporary academia, neglecting rankings and scores, and prioritising intellectual projects that they actually find meaningful regardless of how they will impact their career. Is dark academia so pervasive that this category does not exist at all?

\section{The Decay of Language in Neoliberal Academia}

Based on my experience in various universities and innumerable conversations with academic 
friends and colleagues over the past decade or so, I think there is another aspect of contemporary academia that deserves more scrutiny: the corruption of language. In Politics and the English Language, George Orwell (2002: 966) wrote that 'one ought to recognize that the present political chaos is connected with the decay of language, and that one can probably bring about some improvement by starting at the verbal end'. Neoliberal academia offers plenty of good examples of this Orwellian corruption of language. I would say this is apparent in at least four regards. First, there is the proliferation of empty managerial jargon (including absurd high-sounding titles for 'bullshit' academic-managerial positions) that is now the basic staple of any communication coming from the ranks of academic and corporate bureaucracy, which is often remarked on in the literature and need not be discussed in detail.

Second, language is often deployed in ways that subvert the original meaning of words. This can be seen in at least two regards: in the coining of neologisms and in a radical subversion of established concepts. The phenomenon of academic neologisms is quite interesting. While academics-turned-managers are not famous for their inventiveness, they sometimes still manage to display a sparkle of creativity in how they use language. Unfortunately, the neologisms they come up with would not be out of place in Orwell's Nineteen Eighty-Four. One example is the term 'voluntelling', which is someone 'asking you to do something by pretending to give you a choice, when both of us know you don't really have a choice'. As for the subversion of key concepts, this can be seen, for instance, when university administrators lay off hundreds of staff and simultaneously announce that they are organising workshops on 'resilience' for them. Or, more worryingly, when key principles that should be the very foundation of academic life are distorted. This is the case with 'academic freedom', which is today often perverted into an excuse to peddle whatever ill-conceived idea crosses one's mind, without consideration for academic integrity. As Joan Wallach Scott (2019: 5) remarked: 'The university is not a marketplace of ideas in the sense that any opinion is worth hearing; it is, rather, a place in which "one voluntarily subjects one's own speech to the rules of some sort of 'truth procedure"' (quoting Sitze 2017: 597). With neoliberal academia becoming a marketplace in every sense of the word and academics desperately trying to find new ways to tout their wares (that is, themselves and, possibly, a few original ideas), the 'truth procedure' loses clout and, as every claim, no matter how absurd, is subsumed under the umbrella of 'academic freedom', the way is open for all the whining about 'cancel culture' in universities that we have heard in recent years.

The third instance of the academic corruption of language is linked to what Orwell (2011: 244) described as 'doublethink'-that is, 'the power of holding two contradictory beliefs in one's mind simultaneously, and accepting both of them' (which could also be interpreted as trivial hypocrisy, but we are giving these academics the benefit of doubt here). This, for example, is when university leaders decry the sorry state of the university budgetperhaps due to a pandemic, but not necessarilyand express their sorrow at having to lay off casual staff and other expendables, while at the same time pompously announcing that the university is acquiring assets-a piece of land, for instancebecause a university needs to invest in the future and not remain stuck in the present. Or, similarly, when academics-turned-bureaucrats proudly send out college-wide emails to explain that new subsidies are now available but, to make sure this funding is shared as widely as possible, only permanent staff are eligible. Or, when choosing to axe a 'minor' language from a teaching program due to the limited number of students enrolling in the class, college administrators say they are not eliminating the class, they are simply identifying new 'modalities of language transmission'. Or, again, when high-level university officials correctly identify the problem of precariousness that prevents many of the most talented junior scholars from continuing their academic careers, but as a solution they propose sending everyone 'up or out' of the university after no more than three to five years. 
The fourth and final aspect of this degeneration of language in academia can be found in the discourse of gratitude. In a recent essay, Christian Sorace (2020) has discussed how both the Chinese and the US governments often resort to the language of gratitude. In China, we saw this in the wake of the earthquake that hit Sichuan Province in 2008, when the Chinese Government demanded gratitude for its reconstruction efforts from the survivors of the tragedy, or again in 2020, at the onset of the COVID-19 pandemic. In the United States, President Donald Trump delayed COVID-19 relief cheques because he insisted that his signature be on them to remind American citizens of to whom they owed their gratitude. According to Sorace (2020: 168), 'these hysterical demands reveal the insecurity of sovereign power'. Despite all its pretences of transparency, efficiency, and proper procedures, neoliberal academia works exactly according to this logic. One could argue that, in this, neoliberal academia is no different from the old baronial model of the university, but the latter at least did not go to such lengths to belie its underlying dynamics. Today, even though bureaucracy is omnipresent and there appears to be a bureaucratic procedure for everything, it is easy to miss how the system is still grounded in demands for 'gratitude' and its twin, 'loyalty'. Be grateful to us because you got a promotion; be grateful to us because you had funding for your project; be grateful because we allowed you to use the name of the institution in your grant application; be grateful we let you keep your spot in the crumbling ivory tower. How many times does one have to hear these injunctions in his or her academic life? Then, of course, if a person fails to exhibit loyalty, they are 'ignored, labelled a "troublemaker", or given unappealing teaching duties' (Fleming 2021: 59). The persistence of these unwritten rules, and the lengths to which academics-turned-bureaucrats go to disguise them, shows how the neoliberal university of today suffers from the same insecurity of sovereign power described by Sorace. Once the principle of real academic authority-that is, ideally, knowledge-loses its clout, all that is left is a void that can only be filled by brutal, insecure power.

\section{Eroding the System}

In conclusion, Italian Life and Dark Academia should be read side-by-side, as they discuss two dimensions of the same phenomenon: life in the old baronial university that today is (perhaps) on the verge of extinction, and in the new neoliberal academia with which it is being replaced. These two models are often described as incompatible, with the latter generally presented as a significant upgrade on the former in terms of efficiency, transparency, and even quality-an argument that right-wing critics deploy over and over to push forward the latest round of market reforms in higher education. And it is hard to disagree that being subjected to the arbitrary power of a barone who has not done a shred of original research over the past 30 years hardly represents good practice or an ideal to look back to with nostalgia. Yet, deep down, are the two models of academia really that different?

Having had direct experience of both realities, I would say they have more in common than we usually think. First, both models significantly corrupt the language. The baronial university, too, loves to mask its authoritarianism behind talk of meritocracy and collegiality, even though as a rule, I would say it is more honest regarding its true nature, as its authoritarianism is basically in the open for everyone to see. Second, both systems function according to unwritten rules that stipulate obligations of loyalty and gratitude, no matter the amount of paperwork involved. This logic is so entrenched that even writing this short essay was quite difficult. As I was penning these lines, I kept questioning myself and my motives: is my critique ungenerous considering the many opportunities I have been given by universities over the years? Am I ungrateful considering I am still lucky enough to have a job in a university when many others have lost theirs? But then I remembered what Graeber (2015: 26) wrote about how bureaucratic systems

\footnotetext{
always create a culture of complicity. It's not just that some people get to break the rules-it's that loyalty to the organization is to some degree measured by one's willingness
} 
to pretend this isn't happening. And insofar as

bureaucratic logic is extended to the society

as a whole, all of us start playing along.

This settled it.

The real question is what can be done in such a context? Not much, I am afraid. Fred Moten and Stefano Harney (2004) have argued that academics in the neoliberal university should finally give up any emotional attachment to their labour. However, they also allowed us a glimpse of hope by pointing out that an answer to the current crisis might be found in the 'undercommons' of academia-that is, those people (possibly the majority) who work within the university but look at its drift with dismay. It is in the cooperation between these individuals that occurs below the petrified structures of official power that one can still find hope. Alternatively, we can follow the advice of the late sociologist Erik Olin-Wright, who, in his spiritual testament How to Be an Anticapitalist in the Twenty-First Century (2019: 126), writes that the only feasible strategy today is that of 'eroding' capitalism, which 'also requires dismantling capitalism-that is, changing the rules of the game that make up the power relations of capitalism in such a way as to open up more space for emancipatory alternatives'. This can be achieved by working within the interstices of the capitalist system, even in academia. In universities, this can be done by actively working to promote an authentic open-access culture-not the questionable 'gold' open-access strategies that are all the rage today and which simply represent another example of the perversion of language as this form of 'open access' simply aims to ensure hefty profits for commercial academic publishers. It can also be done by joining unions, or by dedicating time (for those who have this luxury) to 'labours of love' and not only to projects that are simply aimed at scoring points in the eyes of the bureaucrats who run the university. We could also attempt to reappropriate language, calling a spade a spade, or engage in passive resistance-by, for instance, pretending to have not received the umpteenth email from some overzealous administrator requiring that we take yet another online course to get a useless certificate. Or we could simply be nicer to colleagues, students, or, if one is in a position of power, subordinates, avoiding becoming like that university official who, when a friend of mine went to see them with a grievance, told them to hold tight and find consolation in the fact that one day, once they moved up the ladder, they would be able to inflict the same injustice on others. It might be a drop in the ocean, and it surely will not lead to the invention of the flying car, but it is still a first step towards eroding the dark system we experience today. 
This text is taken from Made in China Journal: Volume 6, Issue 2, 2021, edited by Ivan Franceschini and Nicholas Loubere, published 2021 by ANU Press, The Australian National University, Canberra, Australia.

doi.org/10.22459/MIC.06.02.2021.31 